\title{
EL PROBLEMA DE LA SOCIALIZACIÓN EN LA TEORÍA SOCIOLÓGICA GENERAL DE HEINRICH POPITZ
}

\author{
Alexis Emanuel Gros \\ Universidad de Buenos Aires ${ }^{1}$
}

http://dx.doi.org/10.5209/rev_NOMA.2012.v35.n3.42205

\begin{abstract}
Resumen.- En este trabajo intento brindar una visión de conjunto de la poco conocida obra del sociólogo alemán Heinrich Popitz (1925-2002) tomando como punto de partida su tratamiento del problema de la socialización (Sozialisation). Con miras a este objetivo, reconstruyo el modo en que dicho problema es abordado en tres de las sub-teorías que conviven en el seno de su teoría sociológica general (allgemeine soziologische Theorie), a saber: (i) la sub-teoría del poder, (ii) la sub-teoría de la ontogénesis de la subjetividad y (iii) la sub-teoría de las normas sociales.
\end{abstract}

Palabras claves.- Heinrich Popitz, teoría sociológica, socialización, normas sociales, poder

\section{The Problem of Socialization in the General Sociological Theory of Heinrich Popitz}

Abstract.- This paper aims to give an overview of the barely unknown work of the German sociologist Heinrich Popitz (1925-2002) taking as a starting point his account of the problem of socialization (Sozialisation). In order to achieve this aim, I reconstruct the way in which that problem is treated in three of the many sub-theories that coexist within his General Sociological Theory (allgemeine soziologische Theorie), namely: (i) The sub-theory of power, (ii) the subtheory of ontogenesis of subjectivity and (iii) the sub-theory of social norms.

Keywords.- Heinrich Popitz, sociological theory, socialization, social norms, power

\footnotetext{
1 Alexis Emanuel Gros. Licenciado en Sociología, Universidad de Buenos Aires (UBA). Doctorando en Ciencias Sociales (UBA). Becario doctoral CONICET (Consejo Nacional de Investigaciones Científicas y Técnicas, Argentina) con sede de trabajo en el Instituto de Investigaciones Gino Germani (UBA). Auxiliar de investigación del Grupo de Estudios sobre Fenomenología y Etnometodología en la misma institución. Docente de la materia "Fenomenología Social" de la Carrera de Sociología (UBA). En 2012 realizó una estadía de investigación en el Alfred-Schütz-Archiv de la Universität Konstanz financiada por el "Kooperationsnetzwerk: Neue Perspektiven der Kulturtheorie" y el DAAD (Deutscher Akademischer Austauschdienst).
} 
Allgemeine soziologische Theorie, so wie sie hier verstanden wird, bezieht sich nicht auf eine bestimmte Gesellschaft, sondern auf "Gesellschaft". Dies geschieht in dem gleichen Sinne, in dem die Biologie nicht nur spezifische Organismen erforscht, sondern auch Theorien über „den" Organismus entwickelt oder die Linguistik sich nicht nur für einzelnen Sprachen, sondern auch für die Struktur "der" Sprache interessiert. "Gesellschaft" als Thema meint hier, wie der Vergleich bereits nahelegt, nicht irgendein Ding an sich, sondern den Bezug auf alle Gesellschaften, die wir kennen (selbstverständlich einschließlich der Naturvölkerkulturen) und damit auf Gesellschaft, „so, wie wir sie kennen“. Allgemeine soziologische Theorie versucht, Geschichtspunkte zu finden -und in Grundbegriffe zu formulieren-, die auf das Gemeinsam in der Verschiedensartigkeit, auf das Wiederkehrende im Wandel der Erscheinungen abzielen.

Heinrich Popitz ${ }^{2}$

\section{Introducción $^{3}$}

La riqueza de las reflexiones sociológicas de Heinrich Popitz (1925-2002) es inmensa. En sus escritos son abordados de forma profunda y sistemática problemas medulares de la teoría social como el poder, la técnica, las normas sociales y la relatividad cultural, entre otros. No obstante, su obra no goza del prestigio y el reconocimiento merecidos. A pesar de la agudeza y originalidad de sus desarrollos teóricos, que sin dudas le valdrían un lugar junto a autores como Niklas Luhmann, Pierre Bourdieu y Thomas Luckmann entre los clásicos contemporáneos de la sociología, el nombre de Popitz es poco conocido en la escena académica alemana y prácticamente no existen traducciones de sus escritos fundamentales en inglés ni en español. ${ }^{4}$

Enfrentándose a este estado de situación, cientistas sociales como Friedrich Pohlmann, Wolfgang Eßbach y Jochen Dreher han emprendido en los últimos

\footnotetext{
2 "La teoría sociológica general, tal como es entendida aquí, no se refiere a una sociedad determinada sino a 'La Sociedad'. Esto ocurre en el mismo sentido en que la biología no sólo investiga organismos específicos sino también desarrolla teorías sobre 'el' Organismo, o la lingüística no se interesa sólo por lenguajes particulares sino también por la estructura 'del' Lenguaje. 'La Sociedad' como tema quiere decir aquí, como ya la comparación sugiere, no alguna cosa en sí, sino la referencia a todas las sociedades que conocemos (incluidas obviamente las culturas primitivas), y con ello a la sociedad 'tal como la conocemos'. La teoría sociológica general intenta encontrar puntos de vista $-y$ formularlos en conceptos fundamentales- que apuntan a los común en la multiplicidad de la sociedades históricas, a lo que retorna en el cambio de las apariciones" (Popitz, 2006c: 88). Todas las traducciones de las citas y los conceptos de Popitz que se leen en este trabajo me pertenecen.

${ }^{3}$ Deseo agradecer al Dr. Jochen Dreher por introducirme en la obra de este clásico olvidado de la sociología durante mi estadía en la Universität Konstanz y al Dr. Andreas Göttlich por las sugerencias bibliográficas. Debo mencionar también al Dr. Carlos Belvedere por su lectura crítica del texto.

${ }^{4}$ El único libro de Popitz traducido al español es su tesis de doctorado, Der entfremdete Mensch. Zeitkritik und Geschichtsphilosophie des jungen Marx (Cfr. Popitz, 1967; 1971).
} 
años la tarea de rehabilitar y popularizar el pensamiento popitziano en Alemania. En el marco de esta empresa, Pohlmann y Eßbach han publicado Soziale Normen (Popitz, 2006), una compilación de textos cortos del sociólogo de Freiburg. ${ }^{5}$ Por su parte, Dreher, director del Sozialwissenschaftliches Archiv de la Universidad de Konstanz, ${ }^{6}$ se ha encargado recientemente de editar dos libros que contienen Vorlesungen inéditas -Einführung in die Soziologie (Popitz, 2010) y Allgemeine soziologische Theorie (Popitz, 2011) - y ha dictado seminarios de posgrado dedicados íntegramente a la obra del autor.

Al igual que la mayoría de los miembros de la primera generación de sociólogos alemanes de posguerra, Popitz se rehusaba a aceptar las "grandes palabras" ("große Worte") de los sistemas sociológicos omniabarcantes herederos del idealismo alemán (Pohlmann, 2000; Dreher y Walter: 2011). Es por ello que a pesar de que su proyecto intelectual consistía en la formulación de una teoría sociológica general (allgemeine soziologische Theorie), aconsejaba a sus alumnos acercarse a las cuestiones fundamentales del pensamiento sociológico a través del abordaje de problemas particulares, tomando como punto de partida el estudio de una de las tantas sociologías especiales. "Esto será, también en lo que respecta a las preguntas más generales que Uds. le hacen a la sociología, más instructivo y estimulante que la lectura de cualquier sistema global..." (Popitz, 2010: 29).

En el presente trabajo intentaré aplicar este consejo de Popitz al estudio de su propia obra, una obra tan rica y multifacética como la realidad social que busca reflejar. Mi propósito aquí será brindar una visión de conjunto del poco conocido trabajo teórico popitziano tomando como punto de partida su tratamiento de un problema particular, el de la socialización (Sozialisation). Con miras a este objetivo, reconstruiré el modo en que dicha problemática es abordada en tres de las múltiples sub-teorías que conviven en el seno de su pensamiento: (i) la sub-teoría del poder, (ii) la sub-teoría de la ontogénesis de la subjetividad y (iii) la sub-teoría de las normas sociales. Este modo de proceder me obligará a bosquejar, al menos de forma sucinta, los rasgos fundamentales de estas tres facetas de la producción del autor, permitiéndome así brindar un mapeo general de su obra al lector no familiarizado con la misma.

El escrito estará organizado en cinco apartados. (1.) En el primero de ellos realizaré un breve bosquejo biográfico de Popitz y expondré los fundamentos de su proyecto teórico. (2.) En el segundo, daré cuenta de las dos concepciones de la socialización que predominan en la historia del pensamiento sociológico: la mecanicista-holista y la subjetivo-interaccionista. (3.) Luego, presentaré la sub-teoría popitziana del poder y el modo en que el problema de la socialización es leído desde la perspectiva de la misma. (4.) En el cuarto apartado, abordaré la sub-teoría de la ontogénesis de la subjetividad como una teoría de la socialización. (5.) Finalmente, trataré de identificar el

\footnotetext{
${ }^{5}$ A pesar de haber nacido en Berlín, Popitz desempeñó la mayor parte de su vida profesional en Freiburg im Breisgau. Es por ello que, siguiendo a Dreher y Göttlich (2011), me refiero aquí al autor como "el sociólogo de Freiburg".

6 En el Sozialwissenschaftliches Archiv de la Universität Konstanz se encuentran los manuscritos no publicados del autor.
} 
lugar que ocupa la socialización en la sub-teoría popitziana de las normas sociales.

\section{Heinrich Popitz y el proyecto de una teoría sociológica general}

Heinrich Popitz nace el 14 de mayo de 1925 en el seno de una familia berlinesa de clase media. Su madre fallece a temprana edad, y su padre, un reconocido político que militaba en la resistencia contra el régimen nacionalsocialista, es condenado a muerte y ejecutado en 1945 tras el fallido atentado a Adolf Hitler perpetrado por el Conde Von Stauffenberg. Popitz estudia filosofía, economía e historia en las universidades de Heidelberg, Göttingen y Oxford, doctorándose en filosofía bajo la tutela de Karl Jaspers en 1949 con una tesis sobre la teoría de la alienación del joven Marx (Eßbach, 2006). ${ }^{7}$ A comienzos de los años cincuenta, impulsado por el estudio de los escritos marxianos y por un "sentimiento de solidaridad" para con la clase obrera que se remonta a su juventud (Popitz, 2006e: 205), se traslada al Ruhrgebiet, donde junto a su colega y amigo Hans-Paul Bahrdt realiza investigaciones sociológicas empíricas sobre los trabajadores de la industria metalúrgica (lbíd.; Eßbach, 2006; Dreher y Walter, 2010). ${ }^{8}$ En 1957 obtiene su Habilitation en sociología bajo la dirección de Arnold Bergstraesser y es llamado a ocupar el cargo de profesor de la misma disciplina en Basel. Allí permanece hasta 1964, año en que es convocado para ser director del recién fundado Instituto de Sociología (Institut für Soziologie) de la Albert-Ludwigs-Universität Freiburg, cargo que ocupará hasta su retiro en 1992. El primero de abril de 2002, fallece en la ciudad de Freiburg im Breisgau a los 77 años de edad (Eßbach, 2006).

Popitz es ante todo un teórico social heredero de autores clásicos como Georg Simmel, Émile Durkheim y Max Weber. En efecto, si bien se desempeña durante la primera mitad de su vida como filósofo e investigador empírico, es sin dudas en el terreno de la teoría sociológica donde han de buscarse sus aportes más significativos. Su proyecto intelectual maduro, que comienza a perfilarse en los años sesenta y que continúa en vigencia hasta el final de sus días, consiste en la elaboración de una teoría sociológica general (allgemeine soziologische Theorie), esto es, una teoría orientada a identificar y delinear el "esqueleto común (gemeinsames Knochengerüst)" (Pohlmann, 2006: 10) de todas las sociedades que existen, existieron y existirán. Así como la lingüística no estudia solo un lenguaje en particular sino la estructura del Lenguaje en general, la teoría sociológica general popitziana se ocupa de investigar los rasgos fundamentales de La Sociedad (Popitz, 2006c), y no meramente las características del capitalismo moderno, como sucede en las teorías sociológicas de la modernidad de autores como Theodor W. Adorno o Jürgen Habermas (cfr. Rosa et al., 2007). En otras palabras: de lo que se trata para Popitz es de rastrear aquellos "rasgos fundamentales (Grundmerkmale)" (Pohlmann, 2006: 10) que a pesar de la innegable diversidad cultural e histórica

\footnotetext{
${ }^{7}$ Der entfremdete Mensch. Zeitkritik und Geschichtsphilosophie des jungen Marx fue publicada en 1953 y reeditada en una versión reducida en 1967 (cfr. Popitz, 1967).

8 Estas investigaciones empíricas, que marcaron un hito en la sociología alemana de posguerra, fueron publicadas en 1957 bajo los títulos Das Gesellschaftsbild des Arbeiters. Soziologische Untersuchung in der Hüttenindustrie y Technik und Industriearbeit. Soziologische Untersuchungen in der Hüttenindustrie.
} 
se repiten en todas las sociedades, y de fijarlos en un sistema teórico unitario a través de la formulación rigurosa y controlada de una batería de "conceptos fundamentales (Grundbegriffe)" (Popitz, 2006c: 88).

En este empresa, Popitz llega a la conclusión de que existen cuatro "fenómenos basales (Basalphänomene) de la asociación (Vergesellschaftung) ${ }^{9}$ humana", a saber: las normas (Normen), el poder (Macht), la técnica (Technik) y la creatividad (Kreativität) (Pohlmann, 2006: 47). "Sin estructuras normativas y de poder, una estructura técnica de artefactos y (...) creatividad, la asociación humana es impensable" (Ibíd: 49). Desde sus años como profesor en Basel hasta su muerte, Popitz se dedica a explorar cada uno de estos hechos primordiales de la vida social, formulando las cuatro sub-teorías que constituyen las columnas de su teoría sociológica general (Dreher y Walter, 2010). Es fundamental señalar que al lado de estas sub-teorías fundamentales conviven otras de carácter secundario como la sub-teoría de la ontogénesis de la subjetividad y la sub-teoría de los roles sociales. ${ }^{10}$

Tal como señalan Dreher y Walter, la teoría sociológica popitizana debe ser comprendida como una "sociología antropológica (anthropologische Soziologie)", ya que se se trata de un edificio teórico construido sobre cimientos proporcionados por la antropología filosófica del siglo XX desarrollada por Max Scheler, Helmuth Plessner y Arnold Gehlen (Dreher y Walter, 2010). ${ }^{11}$ En efecto, el modo de proceder característico de Popitz consiste en derivar principios sociológicos fundamentales de rasgos universales de la "naturaleza" humana. Así lo hace en su tratamiento de cada uno de los mencionados cuatro fenómenos basales de la vida social (cfr. Popitz, 2000a; 2009; 2006c; 2006d; 2011).

Para resguardar a la antropología filosófica moderna retomada por Popitz de críticas destructivas como la de Max Horkheimer (Horkheimer, 1968a), es preciso señalar que la misma no generaliza de modo irresponsable rasgos histórico-culturales puntuales hipostasiándolos como características

\footnotetext{
${ }^{9}$ Vergesellschaftung es uno de los conceptos centrales de la sociología popitziana. Popitz lo define como el proceso en el que "varios hombres comienzan en algún momento a orientar su comportamiento recíprocamente" volviéndose esta orientación "sucesivamente más intensiva y abarcadora" (Popitz, 2006c: 76). Esta noción fue introducida por Georg Simmel en su Große Soziologie (Simmel, 1958) y es también utilizada por Max Weber en Wirtschaft und Gesellschaft (Weber, 1976). Popitz la utiliza en el sentido simmeliano, como sinónimo de relación social o Wechselwirkung (intercambio de efectos). La traducción de este concepto al español encierra múltiples problemas. En la traducción española de la Große Soziologie, se traduce Vergesellschaftung como "socialización" (Simmel, 1977). Desde mi perspectiva, esta traducción puede causar confusiones con el término Sozialisation, también fundamental en la obra de Popitz. Es por ello que en este trabajo opto por traducir Vergesellschaftung como "asociación" y Sozialisation como "socialización".

${ }^{10}$ La sub-teoría de la ontogénesis de la subjetividad será expuesta en este trabajo debido a su centralidad en lo que respecta al problema de la socialización. Tal como la sub-teoría de los roles sociales, la misma es considerada por Pohlmann como un fragmento o derivado de la sub-teoría popitziana de las normas sociales (Pohlmann, 2006).

11 Es fundamental señalar que la antropología filosófica (philosophische Anthropologie) moderna desarrollada por Scheler, Gehlen y Plessner no es una subdisciplina de la filosofía, sino una escuela de pensamiento del siglo $X X$ en el mismo sentido en que lo son la fenomenología, la teoría crítica, el estructuralismo, el pragmatismo, etc. (Fischer, 2006).
} 
universales de la especie humana. ${ }^{12}$ Se trata más bien de una escuela de pensamiento anti-metafísica que opera en constante diálogo con las ciencias empíricas tanto naturales como humanas colocando a la problemática de la relatividad cultural en primer plano (Fischer, 2006).

El autor de esta tradición que más influye en Popitz es Gehlen (Pohlmann, 2006), aunque el sociólogo de Freiburg también retoma nociones centrales del pensamiento de Plessner como las de posicionalidad excéntrica (exzentrische Positionalität) y artificialidad natural (natürliche Künstlichkeit) (Dreher y Walter, 2010). Para Gehlen, el hombre es un "ser de carencias" (Mängelwesen) (Rehberg, 2003: 81) ${ }^{13}$, un animal que debido a su falta de instintos fijos está condenado a la toma de decisiones. De esta visión del ser humano como "animal-no-fijo (nicht-festgestelltes-Tier)" ${ }^{14}$ (Rehberg, 2003: 81) y "desligado de instintos (instinkt-entbunden)" (Popitz, 2010: 87), Gehlen deduce la necesidad de la institucionalización como descarga (Entlastung) del insoportable apremio de la decisión (Ibíd.; Habermas, 1984; Fischer, 2006). La institucionalización "se muestra como necesaria para la supervivencia de un ser debilitado "por naturaleza' o completamente incapaz de vivir (lebensuntüchtig)" (Habermas, 1984: 102). En otras palabras, Gehlen postula "el rescate del 'ser de carencias" a través de las obligaciones institucionales" (Rehberg, 2003: 81). Por otra parte, el filósofo y sociólogo de Leipzig sostiene que el ser humano es un ser plástico, en el sentido de que posee una amplia capacidad de aprendizaje y adaptación que lo habilita a vivir en las más diversas formas culturales, y productivo, en tanto cuenta con una inmensa capacidad creadora que le permite moldearse a sí mismo de infinitas maneras (Ibíd.). Estas categorías antropológicas gehlenianas: la "Instinktentbundenheit" (Popitz, 2010: 87), la "plasticidad (Plastizität)" (Popitz, 2006d: 63), la "productividad (Produktivität)" (Ibíd.) y la "necesidad de moldeamiento (Formungsbedürftigkeit)" (Popitz, 2011: 133), juegan un rol fundamental en la sociología antropológica de Popitz. ${ }^{15}$

Ahora bien, la teoría sociológica general no se limita a constatar regularidades en la multiplicidad histórico-cultural sino que persigue en última instancia un objetivo mucho más ambicioso: responder a la pregunta par excellence de la reflexión sociológica clásica, ¿cómo es posible la sociedad? Popitz deja esto asentado con claridad en su Antrittsvorlesung de Basel en 1960: "el problema

\footnotetext{
${ }^{12}$ En "Bemerkungen zur philosophischen Anthropologie", Horkheimer lanza una crítica profunda a la antropología filosófica de Max Scheler. "La tarea que Max Scheler le plantea a la antropología, mostrar cómo surgen los monopolios, los productos y las obras específicas del hombre a partir de una estructura fundamental del ser-hombre (Menschensein) (...) es imposible (...) No hay una fórmula que determine de una vez y para siempre la relación entre individuo, sociedad y naturaleza" (Horkheimer, 1968a: 202). Es importante dejar asentado que en la antropología de Scheler perviven ciertos elementos metafísicos que desaparecerán en las posiciones de Plessner y Gehlen. Para un tratamiento de las diferencias entre las posiciones de Scheler, Plessner y Gehlen, véase el excelente texto de Fischer (2006).

${ }^{13}$ Gehlen retoma la noción de Mängelwesen del pensamiento de Johann Gottfried von Herder.

${ }^{14}$ La idea de nicht-festgestelltes-Tier proviene de la obra de Friedrich Nietzsche.

${ }^{15}$ Es importante dejar asentado que Popitz no está solo en su proyecto de elaborar una sociología antropológica. El sociólogo de Freiburg es parte de la escuela antropológicofilosófica en sociología, uno de los tres paradigmas fundamentales de la sociología alemana de posguerra -los otros dos son los de la Escuela de Frankfurt y la Escuela de Köln. La influencia inmensa que tuvo la antropología filosófica moderna en la sociología se debe principalmente al hecho de que los tres fundadores de esa doctrina, Scheler, Plessner y Gehlen, migraron de la filosofía a esta última disciplina (Fischer, 2006).
} 
del que se trata aquí es el de la condición de posibilidad de la vida humana conjunta. Para utilizar una expresión de Durkheim, ¿cómo es posible el `hecho sociedad' ('Tatsache Gesellschaft')? ¿Cómo es posible que los hombres puedan ajustarse recíprocamente con cierta seguridad y durabilidad" (Popitz, 2006d: 74). En su excurso "Wie ist Gesellschaft Möglich?” (¿Cómo es posible la sociedad?) perteneciente a su Große Soziologie, Simmel (1908) intenta resolver este interrogante desde una perspectiva gnoseológica de raigambre kantiana. El sociólogo berlinés considera que la vida social es posible debido a ciertos procesos de conocimiento (Erkenntnisprozesse) que denomina generalizaciones sociales (soziale Verallgemeinerungen). Se trata de un conjunto de tipificaciones y abstracciones que nos permiten ver a nuestros congéneres no como individuos únicos e irrepetibles sino como representantes de roles sociales -"oficiales de policía", "funcionarios", "profesores", "militares", etc. (Popitz, 2006b: 145-146). Si bien las abstracciones y tipificaciones cumplen un rol fundamental en la teoría sociológica popitziana (cfr. Popitz 2006b; 2006c; 2006d; 2011), podría afirmarse que Popitz se inclina por una respuesta más normativa que gnoseológica, y en este sentido, más durkheimiana que simmeliana, al interrogante acerca de las condiciones de posibilidad de la sociedad. Así lo señalan Dreher y Göttlich: "Popitz puso el concepto de norma (Normkonzept) en el centro de su enfrentamiento con la clásica pregunta de Georg Simmel: ¿cómo es posible la sociedad?'” (Dreher y Göttlich, 2011: 390). Las normas son para Popitz "el hecho basal de la existencia social" ('das" Basalfaktum der sozialen Existenz der Menschen) (Pohlmann, 2006: 31), y por tanto, cumplen un rol mucho más importante en su teoría sociológica general que los otros hechos sociales primordiales. El sociólogo de Freiburg sintetiza esta primacía del problema de la normatividad cuando, apoyado en Durkheim, afirma que "toda sociedad es una sociedad moral, una sociedad que moraliza (Jede Gesellschaft ist eine moralische, eine moralisierende Gesellschaft)" (Popitz, 2006c: 86).

A primera vista, la "pretensión de generalidad (Allgemeinheitsanspruch)" (Dreher y Göttlich, 2011: 395) de la teoría sociológica general popitziana es pasible de ser malinterpretada como un rasgo metafísico. A los fines de evitar este error, resulta fundamental dar cuenta de las diferencias insalvables que existen entre el proyecto teórico de Popitz y el pensamiento metafísico en su manifestación sociológica. Como es sabido, la metafísica es la actitud mental prevaleciente en la filosofía occidental desde sus comienzos en la Grecia antigua (Horkheimer, 1968b). Esta actitud aspira a captar la "complexión total del mundo (Gesamtbeschaffenheit der Welt)" (Ibíd.: 38) mediante la razón partiendo de la convicción de que existe una identidad total entre ser y pensamiento. El mundo estaría ordenado racionalmente, y el hombre, en tanto animale rationale, estaría capacitado a captar su estructura a través de la especulación. En una palabra: para la metafísica sería posible acceder a una "conciencia absoluta" (absolutes Bewußtsein) del "ordenamiento absoluto" (absolute Ordnung) del universo (Horkheimer, 1968: 38-39). Podría afirmarse que en el campo del conocimiento sociológico el pensamiento metafísico se reproduce en lo que Popitz denomina las "sociologías universales" (Universalsoziologien) (Popitz, 2010: 21), esto es, en posiciones que pretenden subsumir la totalidad del devenir histórico en una filosofía unitaria de la historia -como la física social de Auguste Comte- o en teorías esencialistas que 
intentan explicar todos los hechos sociales a partir de un principio fundamental -como sucede en el caso de teorías sociológicas imitadoras del idealismo alemán como las de Hans Freyer u Othmar Spann, entre otros (Ibíd.). Enfrentándose a estas posiciones de tinte metafísico, Popitz remarca la imposibilidad de captar de un solo golpe la complejísima realidad social moderna, llamando la atención sobre la insalvable limitación e incompletitud de nuestro saber acerca de la totalidad social en que vivimos (Ibíd.). Partiendo de estas premisas, reivindica la importancia de las "sociologías especiales" (Bindesstrichsoziologien) -la sociología industrial, de la familia, de la religión, etc.-, las cuales pueden brindar una visión de conjunto de la sociedad moderna a través del estudio controlado de fenómenos particulares. En el cultivo de las Bindesstrichsoziologien, señala Popitz, "entra en juego la esperanza de que de esta manera uno pueda acercarse de la forma más exacta y confiable a la realidad social de nuestro tiempo: de que en cierto grado los rasgos fundamentales (Grundzüge) de nuestra realidad social puedan, por decirlo de algún modo, ser captados in nuce [en estos fenómenos parciales]" (Ibíd.: 27).

A los fines de comprender cabalmente la diferencia existente entre la teoría sociológica general y las mencionadas "sociología universales" es fundamental mencionar el rol esencial que juega la interacción o Wechselwirkung entre teoría sociológica e investigación empírica en el proyecto sociológico popitziano. Siguiendo a Theodor Geiger, Popitz cree que una de las tareas más apremiantes de la sociología postmetafísica consiste en "la superación del pecado original de la sociología, el cisma entre teoría e investigación empírica (Überwindung des Erzübels der Soziologie, des Schisma von Theorie und empirischer Forschung)" (Popitz, 2006a: 228). En efecto, el sociólogo de Freiburg está convencido de que la producción teórica debe influir decisivamente en la investigación empírica, y viceversa. Por un lado, la formulación de una teoría sociológica general no debe ser entendida como un fin en sí mismo sino como un medio para fundamentar las investigaciones sociológicas tanto cuantitativas como cualitativas (Dreher y Walter, 2011). Por otro, el material empírico proporcionado por los trabajos etnológicos de autores como Ruth Benedict debe servir para controlar las reflexiones teóricas y así "no perder el suelo debajo de los pies" (Popitz en Dreher y Walter, 2010: 290; cfr. Popitz, 2010). ${ }^{16}$

Para finalizar con esta sucinta presentación del pensamiento popitziano, es preciso decir unas palabras acerca de su particular estilo de escritura. Popitz no se caracteriza, como Durkheim, Talcott Parsons o Habermas, por escribir grandes tratados sociológicos. Antes bien, exceptuando Die gesellschaftliche Konstruktion der Gesellschaft, su producción teórica consiste en un conjunto de

\footnotetext{
${ }^{16}$ El sociólogo de Freiburg tampoco está sólo en este proyecto de fomentar la interacción entre teoría sociológica e investigación empírica. Junto a autores como Ralf Dahrendorf y Dieter Claessens, Popitz pertenece a la primera generación de sociólogos alemanes de posguerra. A las ambiciosas teorías metafísicas de sus predecesores, esta generación le contrapone una sobria confianza en la investigación empírica, un "giro hacia la cosa (Wendung zur Sache)" (Bude y Neidhardt en Dreher y Walter, 2010: 285). Debe señalarse que el desarrollo de la sociología como disciplina no es concebida por Popitz y sus contemporáneos como un fin en sí mismo sino como un modo de contribuir al progreso social y la democratización de la flamante Bundesrepublik Deutschland tras la experiencia traumática del Nacionalsocialismo (Dreher y Walter, 2010).
} 
brillantes e imaginativos artículos cortos que se distinguen por una gran densidad y precisión conceptual. Por este carácter minimalista de su estilo, que se pone de relieve en textos como "Über die Präventivwirkung des Nichtwissens" o "Prozesse der Machtbildung", el sociólogo de Freiburg ha sido señalado como un "maestro de la forma corta (Meister der kleinen Form)" (Pohlmann, 2006: 13).

\section{Definición del concepto de socialización}

Tal como sucede con muchas nociones fundamentales de la sociología, no existe una definición unívoca del concepto de "socialización" en la literatura disciplinar. ${ }^{17}$ No obstante, reelaborando algunos señalamientos del especialista en la temática Klaus Hurrelmann (2008; 2003), es posible construir, aunque sea de modo esquemático, los tipos ideales de dos concepciones enfrentadas del fenómeno que cumplen un rol fundamental en la historia del pensamiento sociológico: (A) una que podríamos denominar holista-mecanicista y (B) otra pasible de ser categorizada como subjetivo-interaccionista.

(A) La primera de ellas tiene un sesgo holista ya que pone el acento en la función que cumple la socialización para la reproducción de la estructura social como totalidad. La socialización es aquí concebida como el proceso por el cual los individuos son integrados a la sociedad y situados en el lugar que ésta les ha asignado. Siguiendo a Hurrelmann, puede afirmarse que esta concepción posee un carácter "adaptativo-mecanicista (anpassungsmechanistisch)" (Hurrelmann, 2008: 254) puesto que en ella el individuo juega un rol primordialmente pasivo, limitándose a internalizar los imperativos sociales. En otras palabras, el niño es pensado aquí como una suerte de tabula rasa en la que se imprimen las normas sociales. Esta concepción suele remontarse a Emile Durkheim $(2009 ; 1986)$, para quien la socialización consiste en la integración a la sociedad del infante, pre-social, egoísta y regido por impulsos inmediatos, a través de mecanismos de coerción social. De acuerdo a Hurrelman esta visión de tinte durkheimiano fue la predominante en el campo académico alemán de los años sesenta, en el cual la socialización era pensada como un proceso de transmisión de conocimientos y habilidades de una generación a la siguiente, transmisión que posibilitaba la incorporación de los niños a la totalidad social (Hurrelmann, 2008).

(B) La segunda concepción, inspirada fundamentalmente en la psicología social de George Herbert Mead y también en algunos elementos del psicoanálisis freudiano, desplaza el eje de la reproducción de la estructura social hacia el desarrollo de la personalidad individual (Ibíd.). La socialización es comprendida aquí como el proceso mediante el cual el infante se convierte en un sujeto, esto es, en un self con identidad definida, capacidad para la auto-reflexión y competencias sociales. Se trata de una definición interaccionista del proceso, ya que para ella el niño desarrolla su subjetividad en "enfrentamiento productivo (produktive Auseinandersetzung)" (lbíd.: 253) con el entorno social primario.

\footnotetext{
${ }^{17}$ El concepto de socialización aparece por primera vez en 1828 en el Oxford Dictionary. Allí es definido del siguiente modo: "to render social, to make fit for living in society" (Hurrelmann, 2008: 253).
} 
En este trabajo partiré de la hipótesis de que en el seno del multifacético pensamiento de Popitz conviven ambas concepciones del problema de la socialización. A continuación intentaré mostrar el modo oscilante en que dicho problema es abordado en tres de las sub-teorías que conforman su teoría sociológica general.

\section{El problema de la socialización en la sub-teoría del poder}

Phänomene der Macht es sin dudas el libro más popular de Popitz en Alemania. ${ }^{18}$ En los artículos contenidos en él, el autor elabora una original teoría del poder sustentada en bases antropológico-filosóficas con el objetivo de brindarle a las ciencias sociales un "marco de referencia general (allgemeiner Bezugsrahmen)" para el análisis de fenómenos empíricos de poder (Popitz, 2009: 11). ${ }^{19}$

En términos generales, Popitz define al poder como la capacidad que posee el hombre "de imponerse frente a fuerzas ajenas (Das Vermögen, sich gegen fremde Kräfte durchzusetzen)" (Ibíd.: 22), ya sea que éstas provengan de la naturaleza -biótica o abiótica- o de otros hombres. En tanto sociólogo, sin embargo, Popitz se interesa particularmente por el poder social, esto es, por aquél poder que los hombres ejercen sobre otros hombres. A los fines de circunscribir claramente este objeto de estudio, el autor retoma la clásica definición de Weber: "poder (Macht) significa toda probabilidad (Chance), dentro de una relación social, de imponer la propia voluntad, incluso contra resistencia, sin importar en qué se funde esta probabilidad" (Weber en Popitz, 2009: 17). De forma preliminar, podría afirmarse entonces que Popitz comprende al poder social como una relación social desigual que consta de dos partes: (i) el hombre o grupo de hombres débil que sufre el poder y (ii) el hombre o grupo de hombres fuerte que lo ejerce. ${ }^{20}$

El sociólogo de Freiburg parte de la premisa de la "omnipresencia del poder (Omnipräsenz von Macht)" en el espacio social (Popitz, 2009: 15). Desde esta posición, el poder no es entendido como un hecho confinado al ámbito de la política sino más bien como un fenómeno presente en todas las formas de relaciones humanas, incluso en aquellas que aparentan ser más inofensivas, como las relaciones entre cónyuges o entre padres e hijos. En una palabra, el poder es "un elemento universal de la asociación humana" (universales Element menschlicher Vergesellschaftung) (Ibíd.: 21), un elemento que determina de raíz todos los modos en que los hombres se vinculan entre sí. ${ }^{21}$

\footnotetext{
${ }^{18}$ Existe una traducción italiana bajo el título Fenomenologia del potere (Cfr. Popitz, 2001).

${ }^{19}$ La presente exposición de la sociología del poder de Popitz se sustenta fundamentalmente en el artículo "Das Konzept Macht" (Popitz, 2009).

${ }^{20}$ Los conceptos de fuerte y débil no son utilizados por Popitz. Antes bien, se trata de términos de los que me valgo para exponer su posición. Es fundamental señalar que la fortaleza o la debilidad no deben ser aquí comprendidas como propiedades absolutas de los sujetos 0 grupos sociales. Se trata más bien de rasgos relacionales: A es fuerte porque posee más recursos económicos, bélicos o de otro tipo que $B$.

${ }^{21}$ Popitz reconstruye las condiciones históricas de posibilidad de esta concepción del poder como fenómeno total. Sólo en la modernidad se vuelve posible la sospecha de la universalidad del poder. A diferencia del hombre del medioevo, el hombre moderno sabe que "no hay órdenes de poder sagrados ni necesarios por naturaleza" (Popitz, 2009: 20). Las reflexiones de
} 
El objetivo principal de las reflexiones popitzianas volcadas en Phänomene der Macht consiste en indagar acerca de las causas de esta universalidad y pervasividad. Dicho propósito se encuentra cristalizado en los interrogantes que aparecen en las primeras páginas de "Das Konzept Macht": "¿en que se basa el poder humano? (Worauf beruht menschliche Macht?)" (Ibíd.: 11), "¿por qué es justificada la sospecha de que el bacilo poder está inserto en todas las relaciones humanas? (Warum ist der Verdacht begründet, dass der Bazillus Macht in allen menschlichen Beziehungen steckt)" (Ibíd.: 21).

Siguiendo el modo de proceder que caracteriza a su sociología antropológica, Popitz apela a desarrollos teóricos de la antropología filosófica para responder a estas preguntas. El poder existe debido a que los hombres de todas las culturas y momentos históricos poseen un costado débil, marcado por ciertas dependencias vitales (vitale Abhängigkeiten), y un costado fuerte, vinculado a ciertas capacidades de acción (Handlungsfähigkeiten) (Ibíd.). Ampliando la definición preliminar recién brindada, podría decirse entonces que el poder es una relación social en la cual (i) las dependencias vitales del hombre o grupo débil son aprovechadas de forma intencional ${ }^{22}$ por (ii) el hombre o grupo fuerte a través del ejercicio de ciertas capacidades de acción. Siguiendo estos lineamientos, Popitz diferencia cuatro formas antropológicas de poder fundamentales (anthropologische Grundformen der Macht) (Ibíd.: 22), cada una de las cuales se corresponde con una pareja complementaria de capacidades de acción y dependencias vitales.

El tratamiento del problema del poder tiene un significado fundamental en el marco de las reflexiones popitzianas en torno a la socialización. En "Das Konzept Macht", Popitz señala: "[d]onde sea que los hombres cuiden y críen niños, ejercen poder de forma intencional y con alta superioridad: poder de acción, poder instrumental, poder autoritativo y poder definidor de datos" (Ibíd.: 35). El poder es siempre "utilizado y debe ser siempre utilizado en el proceso de socialización. Todo niño aprende a tratar con el poder" (Ibíd.). Desde la perspectiva de la teoría del poder, la socialización es concebida entonces como una relación de poder en la cual (i) el débil es el niño y (ii) el fuerte, el adulto.

A continuación presentaré los cuatro tipos de poder diferenciados por Popitz dando cuenta de sus respectivas parejas complementarias de (i) dependencias y (ii) capacidades antropológicas. Siguiendo la convicción popitiziana de que la socialización es un proceso en el que actúan de forma complementaria y solapada las cuatro formas fundamentales de poder, ilustraré la definición de cada una de estas formas con reflexiones acerca de su manifestación en dicho proceso.

1. Poder de acción (Aktionsmacht). "Esta es la primera raíz del poder: los hombres pueden ejercer poder sobre otros hombres porque pueden dañarlos" (lbíd.: 25).

Popitz deben ser entendidas entonces como una explicitación teórica de la creencia implícita en la pervasividad del poder que opera en common sense de la modernidad (Ibíd.).

22 De acuerdo a Popitz, para que pueda hablarse de poder propiamente dicho el aprovechamiento de las dependencias vitales de lo débiles por parte de los fuertes debe ser intencional, es decir, voluntario y consciente. El poder para Popitz implica entonces "el propósito (Absicht) de dañar, el propósito de manejar el comportamientos y las actitudes de otros, el propósito de cambiar sus condiciones de vida" (Ibíd.: 34). 
(i) La dependencia vital del hombre o grupo débil que entra en juego aquí es la vulnerabilidad física. Debido a la exposición (Ausgesetztheit) de su cuerpo, el ser humano es un ser "abierto al daño (verletzungsoffen) en múltiples y sutiles formas" (Ibíd: 24). En efecto, a diferencia de otros animales, el hombre carece de un caparazón, coraza o escudo que pueda proteger sus órganos ante eventuales ataques externos (lbíd.). ${ }^{23}$

(ii) La capacidad de acción esgrimida por el hombre o grupo fuerte para aprovechar la fragilidad física del débil es la fuerza-para-dañar (Verletzungskraft) o violencia (Gewalt). La misma está fundada tanto en la potencia física como en la habilidad e inteligencia humanas para desarrollar armamento y otros medios artificiales destinados a hacer daño (lbíd.: 24). De acuerdo a Popitz, la fantasía de daño (Verletzungsphantasie) humana es infinita, y por tanto también lo es la peligrosidad (Gefährlichkeit) del hombre para el hombre (Ibíd.).

Resulta fundamental señalar que este tipo de poder no se ejerce de forma duradera y sostenida sino de manera puntual o esporádica. Se trata, en efecto, de una forma de poder que se manifiesta en Einzelaktionen, es decir, en acciones $u$ operaciones violentas aisladas (Ibíd.).

El poder de acción en la socialización. El adulto ejerce poder de acción para proteger al niño de riesgos físicos de los que éste es inconsciente. Esto sucede cuando le sustrae violentamente un objeto que puede causarle daño (Ibíd.) o cuando lo desplaza por la fuerza de un sitio potencialmente peligroso. Popitz señala que el proceso de socialización en la más temprana infancia debe ser entendido como una suerte de "adiestramiento (Dressur)" de la conducta (Popitz, 2011: 262). Podría afirmarse que el neonato, que aún no ha desarrollado las estructuras fundamentales del self ni internalizado los elementos básicos del orden normativo, vivencia los correctivos físicos aplicados por los adultos como hechos violentos discontinuos o aislados.

2. Poder instrumental (instrumentelle Macht). "La base de este poder instrumental es el poder-dar (Gebenkönnen) y poder-quitar (Nehmenkönnen), la disposición de recompensas y castigos" (Ibíd.: 26).

(i) Aquí la "preocupación por el futuro" (Sorge um die Zukunft) (lbíd.: 33) constituye la dependencia vital decisiva del débil. ${ }^{24}$ En este tipo de poder, "los motivos que generan conformidad son el miedo y la esperanza" (Ibíd.: 26). Popitz considera que uno de los rasgos antropológicos esenciales es la denominada "orientación-hacia-el-futuro de la acción humana (Zukunftsorientiertheit der menschlichen Handlung)" (lbíd.: 31). El hombre posee expectativas sobre el futuro que no son meramente cognitivas -hipótesis

${ }^{23}$ En mi presentación del poder de acción me centro en la que es para Popitz la forma fundamental de la vulnerabilidad humana: la kreatürliche Verletzbarkeit o vulnerabilidad física. Es preciso dejar asentado que para el autor el hombre es también pasible de ser dañado en sentido económico -cuando se le sustraen bienes básicos de subsistencia- y social-cuando se lo excluye o aísla del grupo al que pertenece.

${ }^{24}$ Si bien Popitz no cita a Martin Heidegger, la idea de que la preocupación por el futuro constituye un rasgo fundamental del hombre tiene reminiscencias heideggerianas. Popitz se vale incluso del término Sorge (cura, cuidado o preocupación), que es central en Sein und Zeit (cfr. Heidegger, 2006). 
o pronósticos- sino fundamentalmente desiderativas. Es decir, ansía o teme determinados acontecimientos por venir (Popitz, 2006c).

(ii) El fuerte se aprovecha de esta dependencia vital a través de su "capacidad para generar miedos y esperanzas (Fähigkeit Angst und Hoffnungen zu erzeugen)" (Ibíd.: 33), capacidad que podría denominarse manipulativa. Debido a que posee ciertos recursos de los que el débil carece, puede prometer recompensas y amenazar con castigos. En este contexto, la promesa de recompensas puede ser entendida como un soborno y la amenaza de castigos, como una extorsión (Ibíd.: 26): "si haces lo que digo, recibirás recompensa; si no, serás castigado". De este modo el fuerte le impone una definición de la situación al débil; lo coloca ante una alternativa, ante un o bien-o bien (Entweder-Oder): su comportamiento futuro será visto o bien como signo de obediencia, o bien como muestra de desobediencia (Ibíd.). Es fundamental señalar aquí que no es necesario que el hombre o grupo fuerte disponga efectivamente de la capacidad de sancionar negativa y positivamente que dice poseer. Es suficiente con que el débil crea que esto es así. Es por ello que muchas veces "la estrategia del ejercicio de poder instrumental consiste en la construcción y mantenimiento de esta credibilidad (Glaubhaftigkeit)" (Ibíd.).

A diferencia de lo que sucede en el poder de acción, este modo de ejercicio del poder no es puntual sino que le permite al fuerte conducir el comportamiento del débil de forma duradera. Aquí "[l]os hombres se convierten duraderamente en instrumento (Werkzeug) de la voluntad ajena" (Ibíd.: 27).

El poder instrumental en la socialización. En un momento ulterior de la maduración, el niño comprende que los actos de violencia aparentemente puntuales y aislados son una sanción negativa que sobreviene como consecuencia de comportamientos incorrectos. El infante entiende ahora que "sus acciones tiene buenas y malas consecuencias, y que otros pueden originar esas consecuencias" (Ibíd.: 35). Los adultos significativos son los "señores sobre el miedo y la esperanza" (Herren über Angst und Hoffnung) del niño. Poseen medios para otorgar sanciones positivas y negativas, y por ello, pueden manipularlo. En tanto ser preocupado por el porvenir, el infante obedece en el presente para evitar castigos u obtener recompensas futuras. En otras palabras: es chantajeado - si se porta mal, será castigado- y sobornado si se porta bien, será recompensado.

3. Poder autoritativo (autoritative Macht). "Uno lleva [a este tipo de poder] siempre consigo como control internalizado (verinnerlichte Kontrolle)" (Ibíd.: 28).

(i) Esta modalidad de poder se sustenta en dos dependencias psíquicas (psychische Abhängigkeiten) características del hombre: su necesidad de patrones (Maßstabs-Bedürftigkeit) y su necesidad de reconocimiento (Anerkennungsbedürftigkeit) (Ibíd.). Por un lado, Popitz considera que, en tanto ser desprovisto de instintos fijos o ser de carencias (Rehberg, 2003; Fischer, 2006), el ser humano precisa de algún tipo de patrón (Maßstab) que oriente y ponga límites a su accionar, descargándolo así del riesgo y la responsabilidad que implica decidir constantemente sobre la propia vida. Por otro, inspirado en Hegel (1991), considera que el hombre precisa percibir signos de reconocimiento (Anerkennung) y confirmación (Bewährung) por parte de un 
alter ego a su vez reconocido como superior para desarrollar su autoestima (Selbstwertgefühl). Este fenómeno es denominado por Popitz doble reconocimiento (zweifache Anerkennung): el débil reconoce al fuerte como superior y, por tanto, desea que éste lo reconozca a él (Ibíd.). ${ }^{25}$

(ii) Las dependencias psíquicas del débil son aprovechadas por el fuerte a través de su capacidad para fijar criterios (Fähigkeit Maßstäbe zu setzen), rasgo que se desprende de la productividad humana, esto es, de la fantasía y fuerza de configuración (Gestaltungskraft) características del hombre (Popitz, 2006d; 2011; Rehberg, 2003).

En contraste con las otras tres formas fundamentales, que constituyen tipos de poder externo (äußere Macht), el poder autoritativo es una modalidad de poder interno (innere Macht) (Popitz, 2009). No se trata de un poder que opera con sanciones externas positivas o negativas sino de un poder acatado voluntariamente, de motus propio por el débil. De acuerdo a Popitz, la inmensa potencia del mismo radica en el hecho de que funciona aún cuando el fuerte está ausente. A la manera del Super-Yo (Über-Ich) freudiano (Freud, 2012), la figura del superior (Überlegene) se internaliza y opera como control interno (Popitz, 2009). El fuerte puede incluso penetrar en el fondo de la subjetividad del débil configurando las actitudes (Einstellungen) y criterios cognitivos y afectivos a través de los cuales éste se vincula con el mundo (lbíd.).

El poder autoritativo en la socialización. El niño reconoce al adulto como superior, y por tanto desea ser reconocido por éste. "[S]e fija a la atención y al reconocimiento de los adultos" (Ibíd:: 35). También busca en el otro significativo los patrones de orientación que necesita para obtener seguridad y confianza en el trato con un mundo circundante novedoso y extraño. En un estadio ulterior de maduración, incorpora los criterios de percepción y acción de la persona de referencia primaria y comienza a auto-controlarse observándose a sí mismo desde la perspectiva de éste último.

4. Poder definidor de datos (Datensetzende Macht). "No es de ninguna manera el poder de las cosas sobre los hombres (...) sino un poder del fabricar (Herstellen) y del fabricante (Hersteller)" (Ibíd.: 31).

Mientras que los otros tres tipos de poder son relaciones sociales directas sujeto-sujeto-, el poder definidor de datos es un "poder mediado por objetos" (objektvermittelte Macht) -sujeto-objeto-sujeto. El fuerte ejerce poder sobre el débil mediante la modificación del mundo objetivo (Popitz, 2009: 31).

(i) La dependencia vital que entra en juego aquí es la referencia obligada del hombre a artefactos o "Angewiesenheit auf Artefakte" (Ibíd.: 33). Podría afirmarse que esta cualidad está ligada a lo que Helmuth Plessner denomina la artificialidad natural (natürliche Künstlichkeit) humana (Dreher y Walter, 2010). Debido a esta cualidad, que se desprende de la Instinktentbundenheit, el hombre debe recurrir necesariamente a artefactos de algún tipo para sobrevivir. Todo ser humano nace inmerso en un mundo artificial sorbeañadido al natural

\footnotetext{
${ }^{25}$ Como es sabido, el problema del reconocimiento (Anerkennung) es tratado por Hegel en su dialéctica de amo y el esclavo (Dialektik von Herrn und Knecht) (cfr. Hegel, 1991). Esta problemática es retomada en desarrollos teóricos actuales como los de Axel Honneth (cfr. Honneth, 2005).
} 
que fue creado por sus antepasados. Este mundo, lo quiera o no, determina y condiciona de forma decisiva sus posibilidades de acción.

(ii) En esta modalidad de poder el fuerte aprovecha la referencia a artefactos del débil a través de la "capacidad para la acción técnica (Fähigkeit zum technischen Handeln)" (Popitz, 2009: 33). Para Popitz, el ser humano es un "tool making animal" (Ibíd.: 32), esto es, un animal que puede modificar su entorno natural generando un mundo de artefactos. Toda acción técnica implica una definición de datos; todo nuevo artefacto le agrega un nuevo Datum al mundo circundante. Al modificar el entorno, el fuerte modifica y determina simultáneamente las condiciones de vida (Lebensbedingungen) del débil. La construcción de caminos, por ejemplo, facilita el tránsito de los hombres, mientras que la construcción de murallas lo bloquea (lbíd.).

El poder definidor de datos en la socialización. El niño nace en un entorno artificial no elegido por él. Debe adaptarse a "un mundo de artefactos construidos por otros" (Ibíd.). Su habitación, que fue diseñada de acuerdo a los criterios de sus padres, condiciona de forma determinante sus capacidades de acción: los barrotes de la cuna le impiden escapar, ciertos objetos ubicados en lugares altos no pueden ser alcanzados, etc.

Podría afirmarse que en la sub-teoría popitziana del poder existe una mixtura de las dos concepciones de la socialización expuestas en el apartado anterior. Por un lado, dado que el poder es pensado como una relación social, puede leerse aquí a la socialización como un proceso interactivo en el cual el niño se enfrenta productivamente con los adultos significativos desarrollando su personalidad. En este sentido, parecería primar la concepción (B) subjetivointeraccionista. No obstante, al menos en lo que respecta a "Das Konzept Macht", Popitz concibe al niño como el partícipe débil de la relación de poder, esto es, como un mero objeto de los actos de violencia, manipulación y castigo del adulto fuerte. "La sensación de la propia inferioridad es parte del saber social de todos los niños" (Ibíd:: 35). Podría afirmarse entonces que la dimensión de la resistencia del infante frente al adulto no es atendida por el autor. Es por ello que en la sub-teoría del poder puede identificarse también la presencia de la concepción (A) holista-mecanicista. Los imperativos del adulto -que puede ser visto como un representante de la sociedad en su conjuntoparecieran ser impresos mecánicamente en la subjetividad infantil. El niño sería integrado a la sociedad mediante el uso planeado y controlado por parte de los adultos de los cuatro tipos de poder.

\section{El problema de la socialización en la sub-teoría de la ontogénesis de la subjetividad}

Como se afirmó más arriba, la concepción (B) subjetivo-interaccionista de la socialización se sustenta en desarrollos teóricos de Freud y Mead, dos pensadores pertenecientes a tradiciones teóricas diferentes pero que confluyen, al menos parcialmente, en sus reflexiones en torno a la ontogénesis de la subjetividad. Ambos coinciden en que el niño no nace siendo sujeto, es decir, como un individuo con identidad definida, capacidad de autorreflexión y competencias sociales. Antes bien, postulan que la subjetividad debe entenderse como el resultado del enfrentamiento productivo del infante con su 
entorno social primario. El momento decisivo de este proceso de subjetivación consiste para ambos en la internalización de las perspectivas de figuras adultas significativas, que conlleva a una escisión de la estructura psíquica en diferentes instancias que "dialogan" entre sí. En suma, tanto Freud como Mead están convencidos de que, lejos de ser un dato primario, la subjetividad es producto de la interacción del niño con su medio familiar, y en este sentido está siempre ya mediada por la intersubjetividad primaria.

Para Freud, el recién nacido es un cuerpo pulsional anárquico. Sólo atravesando el denominado complejo de Edipo (Ödipuskomplex), en el cual el deseo por la madre choca con la prohibición paterna, se convierte en una subjetividad propiamente dicha, esto es, en un individuo portador de un aparato psíquico escindido en tres instancias: Ello (Es), Yo (Ich) y Super-Yo (Über-Ich). A raíz del conflicto desatado por el Edipo, el infante internaliza la perspectiva de la figura paterna, surgiendo de esta manera el Super-Yo, la instancia psíquica portadora de la ley moral de la sociedad. La unidad funcional ejecutiva de la psique, el Yo, debe manejar el conflicto que se desata entre los mandatos y prohibiciones superyóicas y los impulsos inmediatos provenientes del Ello (Freud, 2012).

Salvando las innegables divergencias, Mead sostiene algo análogo cuando afirma que el self, entendido como conciencia capaz de auto-reflexión, surge a través de la internalización de la perspectiva de los otros significativos (significant others) (Schützeichel, 2009; Joas, 2003). A partir de esta internalización, la vida anímica se escinde en dos unidades funcionales: el Yo (I), que "proyecta de forma espontánea y creativa determinados impulsos de comportamiento y posibilidades de acción", y el Mí (me), que "controla las disposiciones del / bajo recurso de reglas sociales" (Schützeichel, 2009: 357).

Siguiendo a estos dos autores, Popitz sostiene que en los primeros meses de vida el infante desarrolla las estructuras fundamentales de la subjetividad en una interacción productiva con su medio primario (Popitz, 2000a; 2000b). "Existe acuerdo en que las estructuras del self (Selbststrukturen) se desarrollan a partir del diálogo social, la interacción del niño consigo mismo a partir de la interacción con otros" (Popitz, 2000a: 36). En "Zur Ontogenese des Selbstbewußtseins. Die Erfahrung der ersten sozialen Negation" y "Zur Entwicklung der Selbststruktur. Selbstempfinden - Selbstbewußtsein Selbstgewißheit”, textos incluidos en Wege der Kreativität, el sociólogo de Freiburg reconstruye la ontogénesis de la subjetividad en la temprana infancia, elaborando una concepción de la socialización de carácter subjetivointeraccionista con ribetes meadianos y freudianos. A continuación bosquejaré las etapas de desarrollo (Entwicklungsetappen) de este proceso ontogenético tal como es descripto por Popitz en los mencionados textos. ${ }^{26}$

Durante los primeros dos meses de vida el infante se limita a satisfacer los pocos reflejos innatos con los que cuenta: "succionar, ver, escuchar y agarrar" (Popitz, 2000a: 39). Entre los tres y los nueves meses, como producto de las primeras interacciones con la madre, adquiere un primitivo sentido de self (sense of self) o autosensación (Selbstempfinden), es decir, "comienza a sentirse a sí mismo como una unidad separada de la madre (von der Mutter

${ }^{26}$ La exposición que sigue combina elementos de los dos textos mencionados. 
getrennte Einheit)" (Ibíd.). En un primer momento, señala Popitz, este sentirsea-sí-mismo es de carácter meramente corporal pero más tarde muta en una percatación de estados internos complejos como sentimientos, motivos e intenciones (lbíd.). Es fundamental señalar que el sense of self no debe confundirse con lo que Popitz denomina autoconciencia (Selbstbewußtsein), esto es, con la capacidad de reflexionar sobre las propias vivencias, habilidad que el niño adquiere aproximadamente a los dos años a través de la internalización de la perspectiva de los otros significativos (Ibíd.). En efecto, para Popitz, el infante "cuenta con Selbstempfinden (sense of self) antes de haber alcanzado una autorreflexión consciente (bewußte Selbstreflexion)" (Ibíd.:41). En este sentido, el Selbstempfinden podría ser homologado con lo que el fenomenólogo danés Dan Zahavi denomina autopercatación prereflexiva (pre-reflective self-awareness), una forma de autoconciencia mínima de carácter no objetivante que implica meramente un sentir las propias vivencias como propias. En resumen, el Selbstempfinden postulado por Popitz es una suerte de self mínimo, no innato sino adquirido, que actúa como condición de posibilidad de modos más complejos de autoconciencia.

Popitz señala que en el viraje del primer al segundo año de edad se produce un salto cualitativo en las capacidades motoras infantiles: el niño puede ahora trepar, caminar y correr, lo cual tiene como consecuencia el surgimiento de un comportamiento explorativo (exploratives Verhalten) y un aumento de la independencia respecto de la madre (Popitz, 2000b). Ésta advierte rápidamente que la recién adquirida autonomía conlleva peligros para su hijo: puede caerse y lastimarse, meter los dedos en el enchufe, ingerir elementos tóxicos, etc. Ante la imposibilidad de mantenerlo bajo control de forma permanente o de "acolchonar" la totalidad del mundo circundante, la madre se ve obligada a idear nuevas formas de comunicación que la habiliten a dirigir el comportamiento del infante desde lejos. En otras palabras, debe generar un nuevo nivel de entendimiento en el niño para enseñarle que hay determinadas cosas que no deben hacerse. Aquí se produce la primera experiencia infantil de la negación social (soziale Negation), la primera prohibición, que para Popitz pone en marcha el proceso de desarrollo de la subjetividad humana. Esta vivencia de ser-impedido (Erlebnis des Gehemmtwerdens) tiene un gran impacto emocional en el niño. Sus impulsos chocan con una gran resistencia que, paradójicamente, procede de la madre, aquél objeto que antes satisfacía todas las necesidades de modo inmediato. Esto da pie a una experiencia de "frustración de nuevo tipo (Frustration neuer Art)" (Ibíd.: 13) con la cual el niño debe arreglárselas de algún modo.

Sustentado en Freud, Popitz señala que el infante precisa hacerse de un método de manejo de conflictos (Methode der Konfliktbewältigung) para lidiar con este insoportable sentimiento de irritación. En esta encrucijada, se produce una contra-reacción productiva (produktive Gegenreaktion) que consiste en la identificación (Identifizierung) inconsciente del niño con la madre (Ibíd.). El sociólogo de Freiburg señala que aquí confluyen dos tipos de impulsos de identificación (Identifizierungsimpulse). El primero es un acto de búsqueda de seguridad afectiva: el niño huye y se resguarda en la madre, aquel lugar donde poco antes hallaba la paz y tranquilidad absolutas. El segundo, por su parte, implica un afán de poder (Streben nach Macht): el infante se identifica con la 
madre para abandonar su posición de debilidad; se apropia de la negación materna como de un arma: "no, tú no debes hacer eso" (Popitz, 2000b: 14).

La identificación con la madre conduce al cambio de perspectivas (Perspektivenwechsel) descripto por Mead en Mind, Self and Society (Mead, 1967; Popitz, 2000b). El niño juega a "madre e hijo" con su muñeco y troca su perspectiva con la materna, aprendiendo de esta forma a "ver al mundo desde la perspectiva de otro, "con otros ojos"" (die Welt aus der Perspektive eines anderen zu sehen, 'mit anderen Augen) (Ibíd.: 14). Es preciso señalar que a esta temprana edad el infante no cuenta todavía con una capacidad desarrollada de empatía (Einfühlung), razón por la cual no debe confundirse el cambio de perspectivas con una comprensión profunda de los estados psíquicos del alter ego. El niño se limita meramente a reproducir un cierto tipo de acción (Aktionstypus), lo cual no implica necesariamente entender cabalmente el punto de vista ajeno (Ibíd.).

Siguiendo a Mead, Popitz señala que el cambio de perspectivas posibilita la autopercepción (Selbstwahrnehmung), condición de posibilidad del desarrollo de la autoconciencia (Selbstbewußtsein). A partir de la adopción de la perspectiva de la madre, se produce el encuentro del infante consigo mismo (Selbstbegegnung): el niño puede ahora verse a sí mismo como niño. "Cuando [el niño] toma realmente o en pensamientos el rol de un otro, necesariamente se confronta a sí mismo como niño" (Ibíd.: 19). La internalización de la perspectiva del otro implica una duplicación del yo (Verdoppelung des Ichs), una escisión (Spaltung) de la vida psíquica en dos instancias, el actor (el Yo o I) y público (el Mí o me). El niño puede ahora reflexionar sobre sus propias vivencias, esto es, objetivarlas y contemplarlas con detenimiento. Ser autoconsciente no implica sin embargo para Popitz meramente tener una conciencia escindida en dos o más instancias, sino también percatarse de la unidad de la propia conciencia en esta escisión. "Yo hablo conmigo. Yo soy las dos cosas. La autoconciencia es la experiencia de que 'yo soy uno y doble' (Ich spreche mit mir. Beides bin ich selbst. Selbstbewußtsein ist die Erfahrung, "daß ich eins und doppel bin)" (Popitz, 2000a: 43). El sociólogo de Freiburg resume sus reflexiones en torno al surgimiento de la Selbstbewußtsein reproduciendo dos conocidas sentencias de Mead: "We must be others, if we are to be ourselves"; "It is only by taking the roles of the others that we have been able to come back to ourselves" (Mead en Popitz, 2000b: 20).

El ultimo paso de este proceso ontogenético es para Popitz el desarrollo de la autocerteza (Selbstgewißheit). Este momento implica la profundización de la recién adquirida autoconciencia a través del "surgimiento y desarrollo de representaciones, de competencias lingüísticas, de capacidades empáticas (empatía y simpatía), etc." (Popitz, 2000a: 43). A través de la interacción continua y repetida con los otros significativos, el niño desarrolla y fortalece competencias fundamentales para la vida en sociedad entre las que se destaca la habilidad de anticipar representativamente el comportamiento ajeno futuro. El infante aprende que determinados comportamientos propios desatan sanciones negativas o positivas del alter ego, y de este modo comienza a proyectar sus acciones futuras de acuerdo a la estructura condicional si-entonces (wenndann): "Si hago $\mathrm{A}$, entonces el alter ego hará $\mathrm{B}$; si hago $\mathrm{C}$, entonces el alter ego hará $D$, etc..." De esta forma, el niño se familiariza con la gramática 
fundamental de la acción social, volviéndose así un sujeto apto para interactuar con sus prójimos con un cierto grado de seguridad y previsibilidad (Popitz, 2000a; 2000b).

\section{El problema de la socialización en la sub-teoría de las normas sociales}

En tanto heredero del individualismo metodológico y el nominalismo social de Simmel (1908) y Weber (1976), Popitz concibe a la sociedad no como una entidad metafísica con existencia independiente a los individuos que la componen -esto es, como una personalidad colectiva o un organismo (Weber, 1976) - sino más bien como un entramado de vínculos interpersonales. El objeto de estudio de la sociología popitziana son las relaciones sociales (soziale Beziehungen) (Weber, 1976) o, para utilizar el término simmeliano preferido por Popitz (Simmel, 1908), las Vergesellschaftungen (asociaciones) en y por las cuales se producen y reproducen las unidades sociales (soziale Einheiten) como el Estado y la familia en la vida cotidiana (Popitz, 2006c; 2011). En otras palabras, de lo que se trata para el sociólogo de Freiburg es de captar a la sociedad "in status nascendi" (Simmel en Popitz, 2011: 21), en su siempre vigente y nunca finalizado surgimiento, evitando así caer en las trampas del realismo social, que hipostasia y endiosa productos parciales de este sempiterno proceso. ${ }^{27}$

En Wirtschaft und Gesellschaft, Weber define a la relación social como "un comportamiento de muchos [individuos] que según su contenido de sentido [está] ajustado y, de este modo, orientado recíprocamente" (Weber en Popitz, 2011: 26. Cursivas propias). De esta definición Popitz retoma la idea de que el rasgo esencial de las Vergesellschaftungen consiste en la orientación recíproca de los comportamientos (Popitz, 2006c; 2011), esto es, en el hecho de que ego decide su propia conducta tomando en consideración la conducta pasada 0 futura de alter ego, y viceversa. Debido a la ya mencionada Zukunftsorietiertheit (orientación-hacia-el futuro) esencial a la acción humana (Popitz, 2009), el autor remarca la importancia de la orientación respecto a comportamientos ajenos futuros en detrimento de la orientación respecto a conductas ya transcurridas. Cuando por ejemplo advertimos que el semáforo está en rojo y nos disponemos a cruzar la avenida por la senda peatonal, orientamos nuestra acción presente -cruzar la acera- en el presupuesto de que los automovilistas que aún no han llegado a la esquina respetarán la señal de tránsito y se detendrán antes de llegar a ella. ${ }^{28}$

Para el sociólogo de Freiburg, este tipo de orientación del comportamiento (Verhaltensorientierung), que actúa de modo casi automático y pre-reflexivo,

\footnotetext{
${ }^{27}$ Popitz esboza este punto de partida weberiano-simmeliano de su teoría sociológica general fundamentalmente en Allgemeine soziologische Theorie (Popitz, 2011). Como señalaré más adelante, pueden encontrarse también en Popitz ribetes estructural-funcionalistas que se contradicen con este punto de partida individualista metodológico y nominalista.

${ }^{28}$ Desde un punto de vista estructural, que privilegia el funcionamiento de la sociedad en su conjunto, Popitz esboza otro argumento para justificar la primacía de la orientación hacia el futuro de la acción. Una sociedad en la que sus miembros sólo se orientaran en comportamientos ajenos pasados sería una "sociedad que hace fila (Schlangstehende Gesellschaft)", y en este sentido, una "sociedad lenta (langsame Gesellschaft)" (Popitz, 2006c: 77).
} 
posee un grado de incerteza insuperable, ya que jamás podemos estar completamente seguros de que el prójimo actuará de acuerdo a nuestro pronóstico. Nuestra Verhaltensorientierung se funda entonces en presupuestos o hipótesis no probadas acerca del comportamiento ajeno por venir (Popitz, 2006c). Es fundamental señalar una vez más con Popitz que estos pronósticos no son meramente cognitivos; antes bien, se trata de expectativas de carácter desiderativo: "las expectativas que determinan las orientaciones de comportamiento son mucho más que un mero cálculo de probabilidad (Wahrscheinlichkeitskalkül). Queremos lo que esperamos o lo tememos" (Popitz, 2006c: 83). En efecto, si nuestra expectativa sobre el comportamiento ajeno no se cumple, no nos vemos meramente sorprendidos sino más bien decepcionados, enojados o frustrados. El incumplimiento de las expectativas puede incluso poner en peligro nuestra vida: si en nuestro ejemplo los automovilistas hacen caso omiso al semáforo en rojo y no se detienen delante de la senda peatonal, podemos ser atropellados en nuestro intento de cruzar. Popitz ilustra estas reflexiones valiéndose de una terminología financiera: "lo que nosotros previsiblemente, supuestamente, haremos es para otros moneda al contado en tanto premisa de sus decisiones actuales. Toda sociedad vive a crédito (Jede Gesellschaft lebt auf Kredit)" (Popitz, 2006c: 77).

Inspirado en Theodor Geiger (Popitz, 2006d; Geißler y Mayer, 2003), Popitz remarca el carácter crucial de la previsibilidad (Voraussehbarkeit) del comportamiento para que la sociedad no entre en quiebra. "No puedo orientarme en la acción futura del otro si no es posible una cierta previsibilidad de su comportamiento. Esa es la condición de posibilidad de la orientación en el comportamiento futuro del otro y con ello de la Vergesellschaftung: la previsibilidad" (Popitz, 2011: 29). La previsibilidad puede ser también comprendida como confianza (Vertrauen) en el otro: "el requisito de este abandonarse (Sich-Verlassen) a la acción futura de otros es la confianza. Donde no hay confianza, sólo son posibles Vergesellschaftungen muy limitadas y rudimentarias" (lbíd.: 78).

Para que la conducta sea previsible y confiable, debe estar sometida a regularidades, es decir, los individuos deben comportarse siempre de un modo similar en situaciones típicas similares. Ahora bien, dado que el hombre es un Mänge/wesen, un ser carente de instintos fijos, su comportamiento no es regular por naturaleza, como sucede en el caso de los peces, las víboras o los ciempiés. Es por ello que la sociedad debe encontrar necesariamente un modo de regularizar la conducta humana. En otras palabras, el problema fundamental que debe resolver toda sociedad para subsistir como tal consiste en limitar las arbitrariedades del comportamiento humano a través de la construcción de regularidades de comportamiento (Verhaltensregelmäßigkeiten). "Estas regularidades de comportamiento no caen del cielo (...) La regularidad del comportamiento humano no está fijada naturalmente sino que es artificial. Es un constructo (Konstrukt)" (Popitz, 2006c: 79).

Para Popitz, la sociedad construye estas regularidades a través de la producción e imposición de normas sociales (soziale Normen). En términos generales, el sociólogo de Freiburg define a la norma social como una regularidad esperada de comportamiento (erwartete Verhaltensregelmäßigkeit) que en caso de desvío (Abweichung) genera una sanción (Santkion) contra el 
desviado. "Llamamos normas de comportamiento a formas de comportamiento que son repetidas regularmente en determinadas situaciones por todos o una determinada categoría de miembros de la sociedad o de un grupo y que en caso de desvío son reafirmadas a través de sanciones negativas contra el desviado" (Popitz, 2006b: 135). Debe señalarse que las sanciones de las que aquí se habla no son individuales sino sociales. No se trata de venganzas personales sino de una desaprobación demostrativa apoyada por la esfera pública del grupo (Gruppenöffentlichkeit): "represalias, discriminación, castigos" (Popitz, 2006d: 69). ${ }^{29}$

Popitz señala que a pesar de la innegable diversidad cultural en lo que respecta al contenido de las normas, la forma en que se construye normativamente la sociedad es la misma en todas las culturas. El qué (Was) de la normatividad puede variar, pero el cómo (Wie) es una constante (Popitz, 2006). ${ }^{30}$ "La 'carcasa' de la vida humana en común (Das 'Gehäuse' menschlichen Zusammenlebens), por decirlo de algún modo, se compone siempre de los mismos ladrillos (Bausteine)" (Ibíd:: 93). Estos ladrillos son los tres tipos fundamentales de normas sociales, a saber: (a) las normas universales (universale Normen), (b) las normas particulares no-recíprocas (nicht-reziproke partikulare Normen) y (c) las normas particulares recíprocas (reziproke partikulare Normen).

(a) Las normas generales son regularidades de comportamiento obligatorias para todos los miembros de una sociedad. Se trata de normas que marcan una cierta igualdad a pesar de las diferencias etarias, de condición sexual, de rol social, etc. - -todos deben respetar al prójimo- (Popitz, 2006c). (b) Las normas particulares no-recíprocas, en cambio, son regularidades de comportamiento obligatorias para una cierta categoría de personas. Al definir ciertas conductas que deben ser cumplidas por personas portadoras de un determinado rol social, ${ }^{31}$ estas normas instauran una diferencia entre los miembros de la sociedad -los niños deben obedecer a los mayores- (Ibíd.). (c) Las normas particulares recíprocas, por su parte, fijan las relaciones entre los miembros de una cierta categoría de personas, construyendo de este modo una reciprocidad insular (insulare Rezipozität) entre los mismos -los hermanos deben ayudarse mutuamente (Ibíd.). ${ }^{32}$

\footnotetext{
${ }^{29}$ Para un tratamiento más profundo del problema de la sanción, véase Popitz $(2011 ; 2006 c)$.

${ }^{30}$ Este reconocimiento de la variabilidad de los contenidos de las normas sociales en diferentes culturas, que se sustenta en el profundo conocimiento de Popitz de la literatura etnológica, no debe ser confundido con el relativismo cultural absoluto de muchos autores posmodernos (cfr. Gellner, 1994). En efecto, el sociólogo de Freiburg señala que existen ciertos hechos biológicos fundamentales -como "la diferencia de géneros, el nacimiento, la niñez, la muerte y el envejecimiento" (Popitz, 2006d: 62)- que se presentan en todas las culturas. Para subsistir y desarrollarse, toda sociedad debe enfrentarse con la tarea de interpretar estos hechos y de someterlos a un cierto orden normativo.

${ }_{31}$ Popitz realiza un profundo tratamiento del problema del rol social inspirado sobre todo en desarrollos teóricos del antropólogo Ralph Linton (cfr. Popitz, 2006b).

${ }^{32}$ Popitz define también otros dos tipos de normas que no trataré aquí en profundidad: las normas de sanción (Sanktionsnormen), que regulan el modo en que deben aplicarse las sanciones ante el desvío del comportamiento, y las normas de limitación (Grenznormen), que demarcan los límites entre las diferentes unidades sociales que componen una sociedad (Popitz, 2006c).
} 
A la luz de la recién brindada de norma social, podría afirmarse de forma preliminar que el riesgo de sanción (Sanktionsrisiko) es lo que motiva a los individuos a regularizar, y de este modo a volver previsible y confiable, su comportamiento. Debido a su preocupación por el futuro, el hombre tendería a cumplir las normas en el presente para evitar sanciones negativas por venir. De este modo, Popitz encuentra respuesta a la pregunta par excellence de la reflexión sociológica clásica: ¿cómo es posible la sociedad? "Las normas limitan evidentemente la arbitrariedad (Willkür) en las relaciones entre hombres. Ellas hacen posible que los hombres puedan ajustarse recíprocamente con cierta seguridad y durabilidad" (Popitz, 2006c: 64). En una palabra, para el sociólogo de Freiburg las normas sociales son la condición de posibilidad de la vida humana conjunta. Como se señaló más arriba, la respuesta popitziana a este interrogante es más durkheimiana que simmeliana, es decir, más normativa que gnoseológica.

Esto no significa, sin embargo, que los procesos cognitivos que Simmel denomina generalizaciones sociales sean dejados de lado por Popitz. Por el contrario, las abstracciones (Abstraktionen) y las tipificaciones (Typisierungen) juegan un rol fundamental en el proceso de construcción normativa de la sociedad. Para Popitz, la estructura básica de una norma es la siguiente: una determinada categoría de persona (el automovilista/ el niño) debe llevar a cabo determinado comportamiento (detenerse antes de llegar a la senda peatonal/ irse a dormir) en determinada situación (ante un semáforo en rojo/ a las diez de la noche) (Popitz, 2006d; 2011).De esta estructura se desprende que la producción e imposición de normas sociales sería imposible sin un sistema de clasificación, es decir, sin ciertos criterios que definan y diferencien de modo objetivo tipos de personas, comportamientos y situaciones (Popitz, 2006d). Visto desde el punto de vista de los actores, esto significa que sólo son aptos para la vida social -esto es, para cumplir su propio rol y orientarse con cierto grado de eficacia en el comportamiento ajeno-, aquellos individuos que pueden reconocer estos tipos en la vida cotidiana, es decir, aquellos que pueden verse a sí mismos como "automovilistas" o "peatones", a los otros como "niños" o "profesores" y a la situación como "un semáforo en rojo" o "una boda". En otras palabras, los individuos no pueden adecuar su comportamiento a las normas vigentes si no poseen esta competencia cognitiva que podría denominarse tipificación (Typisierung) o abstracción (Abstraktion). Se trata de la capacidad de subsumir personas, comportamientos y situaciones concretas bajo tipos abstractos fijados socialmente. Para Popitz, al igual que las normas, esta competencia no es innata sino que debe ser inculcada en el proceso de socialización. "El desafío de toda crianza consiste en (...) imponer una determinada batería de situaciones tipificadas frente a la plenitud de las vivencias de situación (Situationserlebnisse) subjetivo-individuales del niño" (Popitz, 2006d: 65). ${ }^{33}$

Retornando a la pregunta acerca de cómo las normas sociales garantizan la regularidad del comportamiento humano, es preciso señalar que la aseveración preliminar de que los hombres cumplen las normas por miedo a ser

\footnotetext{
${ }^{33}$ Este tratamiento del problema de las tipificaciones es muy similar al llevado a cabo por Alfred Schütz y sus discípulos, Peter Berger y Thomas Luckmann (cfr. Schütz y Luckmann, 2003; Berger y Luckmann, 2010).
} 
sancionados solo refleja parte de la verdad. Inspirado en la idea weberiana de que es imposible que un orden sociopolítico se mantenga de forma duradera sustentado meramente en la coerción (Weber, 1976), Popitz remarca la importancia de la internalización (Verinnerlichung) de las normas para la construcción de Vergesellschaftungen intensas, duraderas y sustentables. En efecto, una sociedad cuyas normas no han sido internalizadas -esto es, asumidas, incorporadas y habitualizadas- adecuadamente por sus miembros está condenada al colapso. Es por ello que para garantizar su continuidad en el tiempo toda sociedad tiene como tarea fundamental procurar que las nuevas generaciones internalicen la estructura normativa. El proceso mediante el cual esto se lleva a cabo es denominado por Popitz socialización (Sozialisation) (Popitz, 2006c; Popitz, 2011). A continuación presentaré el interesante tratamiento popitziano del problema de la internalización para luego bosquejar su abordaje de la socialización desde la perspectiva de esta sub-teoría.

La internalización es para Popitz "la estampación interna del hombre en el sentido de las normas vigentes (innerliche Prägung des Menschen im Sinne der geltenden Normen)" (Popitz, 2011: 258). En otras palabras, se trata del proceso por el cual las normas sociales pasan de ser imposiciones de afuera a "obviedades de adentro" (Selbstverständlichkeiten von innen) (Popitz, 2006d: 73). El autor reconoce dos tipos básicos de internalización: (a) la internalización habitualizada (habitualisierte Verinnerlichung) y (b) la internalización nohabitualizada (nicht-habitualisierte Verinnerlichung) (Ibíd.).

(a) Como lo indica su nombre, la primera implica un proceso de habitualización (Habitualisierung) en el cual el individuo aprende a hacer de modo automático, esto es, sin necesidad de control externo ni reflexión, aquello que debe hacer. Las normas de costumbre (Gewohnheitsnormen) permanecen bajo el umbral de la conciencia. Se han naturalizado y de este modo se han tornado invisibles. Gracias a ello, el sujeto no se da cuenta de que su comportamiento no es necesario sino contingente; no advierte que existen modos alternativos de actuar que han sido obliterados. Sustentado nuevamente en Gehlen, Popitz señala que la naturalización conduce a una descarga de la presión de la decisión (Entlastung von Entscheidungsdruck) que resulta ventajosa y saludable para el hombre. "Gracias a dios no nos damos cuenta en la cotidianeidad de que podríamos actuar de otro modo" (Popitz, 2011: 265). ${ }^{34}$ (b) En contraste, las normas de conciencia moral (Gewissensnormen), propias de la segunda modalidad de internalización, no funcionan de un modo tan aproblemático. Se trata de exigencias que nos fueron inculcadas por la sociedad pero que se manifiestan como demandas que surgen de nuestra conciencia moral (Gewissen). Cuando lo que hacemos choca contra lo que nuestra conciencia moral dice que deberíamos hacer, se desata un conflicto interno en el que la conciencia se escinde en dos instancias: una que juzga y otra que es juzgada. Estas reflexiones popitzianas recuerdan nuevamente al Super-Yo freudiano (Ibíd.; cfr. Freud, 2012).

Sustentado en desarrollos de Geiger, el sociólogo de Freiburg introduce algunas distinciones conceptuales adicionales para precisar aún más su

\footnotetext{
${ }^{34}$ Pueden rastrearse similitudes entre el abordaje popitziano del problema de la habitualización y las reflexiones de Pierre Bourdieu en torno al habitus (cfr. Bourdieu, 1999). El problema de la corporalidad, sin embargo, no es tratado en profundidad por Popitz.
} 
tratamiento de la existencia interna (innere Existenz) de las normas. Popitz señala que la conciencia de la norma (Normbewußtsein) consta de dos partes: (1.) una parte cognitiva, que denomina Ordnungssicherheit (seguridad sobre el orden), y (2.) una parte desiderativa o valorativa, que llama Legitimitätsglaube (creencia en la legitimidad).

(1.) La Ordnungssicherheit puede ser a su vez escindida analíticamente en dos elementos: (1.1) la Orientierungssicherheit (seguridad de orientación) y la (1.2.) Realisierungssicherheit (seguridad de realización).

(1.1) La primera se refiere al saber que poseen los sujetos acerca de las normas vigentes: “¿qué saben los hombres sobre las normas vigentes?” (Ibíd.: 255) Aquí la palabra seguridad (Sicherheit) es utilizada en el sentido de certus, de información o conocimiento. El acervo de tipificaciones juega un rol fundamental en la constitución de una suerte de mapa normativo que permite a los individuos orientarse en el espacio social. (1.2). En la seguridad de realización, en cambio, la idea de seguridad es pensada en el sentido de securus. Se trata aquí del saber, más intuitivo que intelectual, acerca del grado de validez de las normas, esto es, de si las normas son obedecidas o no y de si existe sanción social en caso de desvío.

(2.) Como es sabido, el concepto de legitimidad proviene de la sociología de la dominación de Weber (1976). En contraste con la seguridad sobre el orden, la creencia en la legitimidad no es un fenómeno cognitivo sino desiderativo. Se trata de una toma de posición valorativa (wertende Stellungnahme) respecto a las normas sociales vigentes (Popitz, 2011). Tomar algo como legítimo significa concebirlo como obligatorio, es decir, reconocer un deber como tal y aceptarlo. Cuando hay creencia en la legitimidad de un orden social o político, no se obedece por costumbre, por interés ni por miedo a una sanción negativa, sino simplemente porque se cree que el mismo está justificado de alguna forma (Weber, 1976).

En suma, para internalizar el ordenamiento normativo de modo adecuado los individuos deben I. habitualizar ciertas normas, II. desarrollar una conciencia moral (Gewissen), III. adquirir un conocimiento adecuado del orden normativo o seguridad sobre el orden (Ordnungssicherheit) y IV. desarrollar una creencia en la legitimidad (Legitimitätsglaube) del mismo. El proceso mediante el cual la sociedad logra que sus miembros internalicen las normas en estos cuatro sentidos es la socialización.

Paradójicamente, podría afirmarse que a la hora de tratar el problema de la socialización desde la perspectiva de la sub-teoría de las normas, Popitz abandona su punto de partida individualista metodológico y nominalista para adoptar una posición teórica afín a la del estructural-funcionalismo. En este contexto, el autor define a la sociedad ya no como un entramado de relaciones sociales o asociaciones sino como "un grupo social cerrado hacia afuera que, al menos parcialmente, se auto-recluta biológicamente e integra socialmente a los recién nacidos" (Popitz, 2006c: 94). La sociedad aparece aquí como Sociedad -es decir, como una entidad substantiva con existencia 
independiente a los individuos que la componen-, y la socialización, como un pre-requisito funcional de la misma. ${ }^{35}$

De acuerdo a Popitz, toda Sociedad aspira a conservar su identidad, pero para lograrlo debe superar el escollo inevitable del cambio generacional. En otras palabras, si la totalidad social pretende mantener su continuidad a lo largo del tiempo, está obligada a integrar de alguna forma a los "recién llegados endógenos (endogene Neuankömmlinge)" (Popitz, 2006c: 102). "La continuidad requiere que los valores y normas, los conocimientos y las capacidades puedan ser transportados a través del umbral generacional. Una sociedad mantiene su continuidad en tanto se muestra capaz de transmisión (Tradierungsfähig), capaz de tradición (Traditionsfähig)" (Ibíd.). En este marco, la socialización es pensada como una tarea (Aufgabe) que la Sociedad debe cumplir para no perecer. Tal como sucede con otras funciones sociales vitales como la producción de alimentos y el castigo de desvíos normativos, el proceso de crianza (Erziehung) no puede entonces dejarse librado al azar sino que debe ser cuidadosamente planeado y ejecutado. "[L]os procesos de internalización no sólo son planificables sino que deben ser planeados en toda sociedad. Si se quiere lograr que las normas sociales sean transmitidas de una generación a la siguiente, (...) debe planearse este proceso que se denomina con el nombre global de socialización (Sozialisation)" (Popitz, 2011: 260).

Ahora bien, ¿de qué modo planea y ejecuta una Sociedad la socialización de los recién llegados endógenos? Popitz responde que lo hace tendiendo una "red normativa sobre la cuna" de los niños (Popitz, 2006c: 103). Desde antes del nacimiento del infante, la Sociedad ha predispuesto una estructura social diseñada especialmente para recibirlo: la estructura de integración (Integrationsstruktur). Se trata de una carcasa social primaria (primäres soziales Gehäuse) que tiene como función satisfacer las necesidades primarias del niño y transmitirle los contenidos normativos fundamentales de la sociedad. En esta unidad social primordial, que en Occidente recibe el nombre de familia, juegan un rol central las denominadas personas de referencia primaria (primäre Bezugspersonen), las cuales se valen conscientemente de la significatividad afectiva que el niño les adscribe para inculcarle al mismo el ordenamiento normativo vigente (lbíd.; Popitz, 2009). ${ }^{36}$

A la luz de lo expuesto, puede señalarse que en el contexto de la sub-teoría popitziana de las normas sociales la concepción preponderante de la socialización es la (A) holista-mecanicista. Popitz pone el acento aquí no en el desarrollo de la personalidad individual sino en la reproducción de la totalidad

35 En los textos de Popitz pueden encontrarse referencias a clásicos del estructuralfuncionalismo en antropología como Bronislaw Malinowski y Alfred Radcliffe-Brown. Muchos de estos elementos estructural-funcionalistas pueden ser rastreados en las reflexiones vertidas en Einführung in die Soziologie (Popitz, 2010).

36 Como se desprende de lo expuesto, las reflexiones popitzianas se concentran fundamentalmente en lo que suele denominarse la socialización primaria, esto es, el proceso de internalización que tienen lugar en la temprana infancia (Berger y Luckmann, 2010). Sin embargo, el sociólogo de Freiburg considera que la socialización no se interrumpe una vez finalizada la niñez sino que continúa en la adultez en la vida profesional y en instituciones como la universidad (Popitz, 2011). En este sentido, puede afirmarse que Popitz reconoce la importancia del proceso de socialización secundaria (Berger y Luckmann, 2010) aunque no lo describa en profundidad en sus textos. 
social. En efecto, la socialización es pensada aquí como una tarea vital que la Sociedad debe planear cuidadosamente para mantener su identidad en el tiempo. En este marco, Popitz concibe a la crianza como una transmisión mecánica de contenidos normativos que tiene lugar fundamentalmente en el seno de la estructura de integración o carcasa social primaria.

\section{Palabras finales}

Este escrito tuvo como propósito presentar una visión de conjunto de la poco conocida obra de Popitz a través del análisis de un fenómeno particular, el de la socialización.

Luego de realizar un bosquejo biográfico del autor y de enunciar los lineamientos centrales de su proyecto intelectual (1.), presenté, siguiendo a Hurrelmann (2008; 2003), los tipos ideales de las dos concepciones antagónicas del fenómeno de socialización que conviven en la historia del pensamiento sociológico: el (A) holista-mecanicista y el (B) subjetivointeraccionista (2.). En los últimos apartados (3.), (4.) y (5.), presenté tres de las sub-teorías que conviven en el edificio sociológico popitziano -la sub-teoría del poder, la sub-teoría de la ontogénesis de la subjetividad y la sub-teoría de las normas- e intenté analizar el modo en que la problemática de la socialización es leída desde la perspectiva de cada una de ellas.

Como conclusión, puede señalarse que las dos maneras de concebir el proceso de socialización, la (A) holista-mecanicista y la (B) subjetivointeraccionista, coexisten en el pensamiento popitziano. En efecto, dependiendo de la sub-teoría en la que esté operando, Popitz enfatiza una concepción del fenómeno sobre la otra. Así, desde la perspectiva de la subteoría de las normas, la socialización es concebida ante todo de un modo (A) holista-mecanicista, mientras que desde el punto de vista de la sub-teoría de la ontogénesis de la subjetividad prima la visión (B) subjetivo-interaccionista. En la sub-teoría del poder, en cambio, puede encontrarse una visión híbrida del problema: elementos de la concepción (A) conviven con elementos de la concepción (B). 


\section{Referencias bibliográficas}

Berger, P.L. y Luckmann, T. (2010). Die gesellschaftliche Konstruktion der Wirklichkeit. Frankfurt am Main: Fischer.

Bourdieu, P. (1999). Meditaciones pascalianas. Barcelona: Anagrama.

Dreher J. y Göttlich A. (2011). Nachwort. En H. Popitz, Allgemeine soziologische Theorie, J. Dreher y A. Göttlich (eds.). Konstanz: Konstanz University Press.

Dreher J. y Walter, M. K. (2010). Nachwort. En H Popitz, Einführung in die Soziologie, J. Dreher y M. K. Walter (eds.) Konstanz: Konstanz University Press.

Durkheim, E. (2009). Educación y sociología. Madrid: Popular.

Durkheim, E. (1986). Les règles de la méthode sociologique. Paris: Presses Universitaires de France. 
Eßbach, W. (2006). In memoriam Heinrich Popitz (1925-2002). En H. Popitz, Soziale Normen, F. Pohlmann y W. Eßbach (eds.). Frankfurt am Main: Suhrkamp.

Fischer, J. (2006). Philosophische Anthropologie - Ein Wirkungsvoller Denkansatz in der deutschen Soziologie nach 1945. En Zeitschrift für Soziologie, 35, 5. Stuttgart: Lucius \& Lucius Verlag. pp. 322-347.

Freud, S. (2012). Abriss der Psychoanalyse. Stuttgart: Reclam.

Gehlen, A. (1950). Der Mensch, seine Natur und seine Stellung in der Welt. Bonn: Athenäum-Verlag.

Geißler, R. y Mayer, T (2003). Theodor Geiger. En D. Kaesler (ed.), Klassiker der Soziologie. Von Auguste Comte bis Alfred Schütz. München: C.H. Beck.

Gellner, E. (1994). Posmodernismo, razón y religión. Buenos Aires: Paidós.

Habermas, J. (1984). Philosophisch-politische Profile. Wozu noch Philosophie? Frankfurt am Main: Suhrkamp.

Hegel, G.W.F, (1991). Fenomenología del espíritu. México D.F.: Fondo de Cultura.

Heidegger, M. (2006). Sein und Zeit. Tübingen: Max Niemeyer.

Honneth, A. (2005). Verdinglichung. Frankfurt am Main: Suhrkamp.

Horkheimer, M. (1968a). Bemerkungen zur philosophischen Anthropologie. En M. Horheimer, Kritische Theorie, A. Schmidt (ed.). Frankfurt am Main: Fischer.

Horkheimer, N. (1968b). Materialismus und Methaphysik. En M. Horkheimer, Kritische Theorie, A. Schmidt (ed.). Frankfurt am Main: Fischer.

Hurrelmann, K. (2008). Sozialisation. En S. Farzin y S. Jordan (eds.), Lexikon Soziologie und Sozialtheorie. Stuttgart: Reclam.

Hurrelmann, K. (2003). Einführung in die Sozialisationstheorie. Basel: Beltz.

Joas, H. (2003). George Herbert Mead. En D. Kaesler (ed.), Klassiker der Soziologie. Von Auguste Comte bis Alfred Schütz. München: C.H. Beck.

Mead, G. H. (1967). Mind, Self and Society from the Standpoint of a Social Behaviorist. Chicago: The University of Chicago Press.

Pohlmann, F. (2006). Heinrich Popitz - Sein Denken und Werk. En H. Popitz, Soziale Normen, F. Pohlmann y W. Eßbach (eds.). Frankfurt am Main: Suhrkamp.

Popitz, H. (2011). Allgemeine soziologische Theorie. J. Dreher y A. Göttlich (eds.). Konstanz: Konstanz University Press.

Popitz, H. (2010). Einführung in die Soziologie, J. Dreher y M. Walter (eds.). Konstanz: Konstanz University Press.

Popitz, H. (2009). Das Konzept Macht. En H. Popitz, Phänomene der Macht. Tübingen: Mohr Siebeck.

Popitz, H. (2006a). Begegnungen mit Theodor Geiger. Einführung. En H. Popitz, Soziale Normen, F. Pohlmann y W. Eßbach (eds.). Frankfurt am Main: Suhrkamp. 
Popitz, H. (2006b). Der Begriff der sozialen Rolle als Element der soziologischen Theorie. En H. Popitz, Soziale Normen, F. Pohlmann y W. Eßbach (eds.). Frankfurt am Main: Suhrkamp.

Popitz, H. (2006c). Die normative Konstruktion der Wirklichkeit. En H. Popitz, Soziale Normen, F. Pohlmann y W. Eßbach (eds.). Frankfurt am Main: Suhrkamp.

Popitz, H. (2006d). Soziale Normen. En H. Popitz, Soziale Normen, F. Pohlmann y W. Eßbach (eds.). Frankfurt am Main: Suhrkamp.

Popitz, H. (2006e). Zum Wiederbeginn der Soziologie in Deutschland nach dem Kriege. En H. Popitz, Soziale Normen, F. Pohlmann y W. Eßbach (eds.). Frankfurt am Main: Suhrkamp.

Popitz, H. (2001). Fenomenologia del potere. Autorità, dominio, violenza, técnica. Bologna: III Mulino.

Popitz, H. (2000a). Zur Entwiclkung der Selbststruktur. Selbstempfinden Selbstbewußtsein - Selbstgewißheit. En H. Popitz, Wege der Kreativität. Tübingen: Mohr Siebeck.

Popitz, H. (2000b). Zur Ontogenese des Selbstbewußtseins. Die Erfahrung der ersten sozialen Negation. En H. Popitz, Wege der Kreativität. Tübingen: Mohr Siebeck.

Popitz, H. (2000c). Wege der Kreativität. Erkunden, Gestalten, Sinnstiften. En H. Popitz, Wege der Kreativität. Tübingen: Mohr Siebeck.

Popitz, H. (1971). El hombre alienado. Buenos Aires: Sur.

Popitz, H. (1967). Der entfremdete Mensch. Zeitkritik und Geschichtsphilosophie des jungen Marx. Frankfurt am Main: Europäische Verlaganstalt.

Rehberg, K.S. (2003). Hans Freyer (1887-1968) - Arnold Gehlen (1904-1976) Helmut Schelsky (1912-1984). En D. Kaesler (ed. ), Klassiker der Soziologie. Von Talcott Parsons bis Anthony Giddens. München: C.H. Beck.

Rosa, H., Strecker, D y Kottmann, A. (2007). Soziologische Theorien. Konstanz: UVK.

Schütz, A. y Luckmann, T. (2003). Strukturen der Lebenswelt. Konstanz: UVK.

Schützeichel, R. (2009). George Herbert Mead. En S. Jordan y B. Mojsisch (eds.). Philosophen-lexikon. Stuttgart: Reclam.

Simmel, G. (1977). Sociología. Estudios sobre las formas de socialización. Madrid: Revista de Occidente.

Simmel, G. (1908). Soziologie. Untersuchungen über die Formen der Vergesellschaftung. Leipzig: Duncker und Humblot.

Weber, M. (1984). Soziologische Grundbegriffe. Tübingen: Mohr Siebeck.

Weber, M. (1976). Wirtschaft und Gesellschaft. Tübingen: J.C.B. Mohr.

Zahavi, D. (2003). Inner time-consciousness and pre-reflective self-awareness. D. Welton (ed.), The new Husserl. A critical reader. Indiana: Indiana University Press. 